\title{
PENGARUH MODEL ELICITING ACTIVITIES (MEA'S) TERHADAP KEMAMPUAN PEMECAHAN MASALAH MATEMATIS DAN SELF CONFIDENCE SISWA
}

\author{
Try Apriani Atieka ${ }^{1}$, Irma Budiana ${ }^{2}$ \\ Sekolah Tinggi Ilmu Tarbiyah Islamic Village Tangerang \\ Email: ${ }^{1}$ triapriani15@gmail.com, ${ }^{2}$ irmabudianaa@gmail.com
}

\begin{abstract}
Abstrak
Penelitian ini bertujuan untuk mengetahui pengaruh Model Eliciting Activities (MEA's) dan konvensional terhadap kemampuan pemecahan masalah matematis dan self confidence siswa. Penelitian ini dilaksanakan di SMP Negeri 9 Tangerang tahun ajaran 2016/2017. Desain penelitian ini adalah post-test eksperimen dan kontrol grup desain. Metode penelitian yang digunakan adalah metode quasi experiment (eksperimen semu). Kelas eksperimen diberi perlakuan berupa MEA's, sedangkan kelas kontrol secara konvensional. Populasi terjangkau penelitian ini adalah siswa SMP Negeri 9 Kota Tangerang kelas VII tahun ajaran 2016/2017 yang berasal dari populasi yang berdistribusi normal, memiliki varians yang sama atau homogen, dan memiliki kesamaan rata-rata. Instrumen yang digunakan terdiri dari tes kemampuan pemecahan masalah matematis, tes kemampuan awal matematika dan angket self confidence matematika. Instrumen tersebut telah melalui uji validitas dan reliabilitas. Analisis data dilakukan dengan uji Anava dua jalur. Berdasarkan hasil penelitian, ditemukan bahwa: (1) kemampuan pemecahan masalah matematis siswa yang belajar dengan MEA's lebih tinggi dibandingkan kemampuan pemecahan masalah matematis siswa yang belajar dengan model konvensional. (2) terdapat peningkatan kemampuan pemecahan masalah matematis siswa yang dipengaruhi oleh kemampuan awal matematika dan model pembelajaran (3) kemampuan pemecahan masalah matematis siswa yang diberi perlakuan MEA's lebih tinggi dibandingkan dengan siswa yang diberi perlakuan model konvensional pada kelompok siswa yang memiliki kemampuan awal matematika tinggi. (4) tidak terdapat perbedaan kemampuan pemecahan masalah siswa antara siswa yang diberi perlakuan dengan MEA's dan siswa yang diberi perlakuan model konvensional pada kelompok siswa yang memiliki kemampuan awal matematika rendah. (5) self confidence siswa dalam belajar matematika yang diberi perlakuan MEA's lebih tinggi dibandingkan dengan self confidence siswa yang diberi perlakuan model konvensional.
\end{abstract}

Kata Kunci: Kemampuan Pemecahan Masalah Matematis, Self Confidence, Model Eliciting Activities (MEA's), Model Konvensional

\begin{abstract}
The purpose of this research are knowing effect of Model Eliciting Activities (MEA's) and Conventional Learning Models to problem solving abilities in mathematics and students self confidence.The research was conducted at SMP Negeri of Tangerang for academic year 2016/2017. Design of this research is post-test only experiment and control group design. The method that used on this research was quasi experiment. Experiment class was treated by MEA's, while control class was treated by conventional model. Accessible population of this research was middle school students at SMP Negeri 9 of Tangerang in grade VII for academic year 2016/2017 based on normal distribution, homogeneous variance, and equality of means. The instruments consist problem solving abilities test, prior knowledge of matematics test and questionnaire of mathematics self confidence. The instruments have been valid and reliable. Analysis data used by Anova 2 way.
\end{abstract}




\begin{abstract}
The result show that: (1) The ability of mathematics problem solving of students who are given $M E A$ 's is higher than the students who are given conventional Learning Models. (2) There is an enhancement of mathematics problem solving of students effected by prior knowledge of mathematics and Mathematics Learning Models.(3) The ability of mathematics problem solving of students with high KAM who are given MEA's is higher than the students who are given Conventional Learning Model. (4) There is no significant difference The ability of mathematics problem solving between students low KAM who given treatment by MEA's and students who are given treatment by Conventional Learning Model. (5) Mathematics Self Confidence of students who are given treatment by MEA's is higher than students who are given treatment by Conventional Learning Model
\end{abstract}

Keywords: The ability of mathematics problem solving, Self Confidence, Model Eliciting Activities (MEA's), Conventional Learning Model

\title{
PENDAHULUAN
}

Matematika merupakan mata pelajaran yang penting. Menurut Chambers (2008) matematika adalah fakta-fakta objektif, sebuah studi tentang alasan dan logika, sebuah sistem di sekitar kita yang murni dan cantik, bebas dari pengaruh sosial, berdiri sendiri, dan mempunyai struktur yang saling berhubungan. Matematika dikarakteristikan sebagai sebuah alat untuk menyelesaikan masalah, tiang penyokong ilmu pengetahuan dan teknologi, dan menyediakan jalan untuk memodelkan situasi yang nyata. Salah satu alasan kurikulum 2013 dirancang oleh Kementrian Pendidikan dan Kebudayaan (Kemendikbud) karena hampir semua siswa Indonesia hanya menguasai pelajaran sampai level 3 (C3), sementara negara lain banyak yang sampai level lebih tinggi. Pencapaian hasil belajar matematika siswa kelas VIII Indonesia menurut benchmark Internasional 2011 (Badan Penelitian dan Pengembangan Pendidikan, 2012) yang mengukur dimensi konten dan dimensi kognitif, siswa Indonesia berada pada level rendah dengan nilai 386, dibandingkan dengan hasil TIMSS sebelumnya.

Pencapaian pada level rendah mengandung makna pencapaian kemampuan yang ditunjukkan oleh siswa yang memiliki pengetahuan tentang bilangan bulat dan desimal, operasi, dan grafik dasar. Perolehan persentase tiap level menunjukkan bahwa siswa Indonesia belum mampu mencapai level mahir yang artinya belum mampu memberikan alasan berdasarkan informasi, menarik kesimpulan, membuat generalisasi, dan memecahkan masalah matematis. Umumnya siswa belum dapat menyelesaikan soal yang diberikan guru apabila guru memberikan soal yang levelnya lebih tinggi, siswa merasa bingung dan kesulitan dalam menyelesaikan soal yang diberikan.

Hasil wawancara dengan guru SMPN di kecamatan Cibodas Tangerang, saat siswa diberikan soal cerita, guru berpendapat siswa cenderung merasa kesulitan untuk mengerjakannya. Sebagian siswa masih belum dapat memahami soal yang diberikan, selain itu siswa lebih terpaku pada rumus yang akan digunakan untuk menyelesaikan soal tersebut. Akibatnya, hasil tes matematika menjadi rendah. Berdasarkan pemaparan di atas, pembelajaran matematika di sekolah belum cukup mampu untuk mencapai tujuan pembelajaran matematika.

Banyak faktor yang menyebabkan siswa tidak mampu menyelesaikan soal cerita. Kelemahan ini timbul disebabkan siswa masih belum terbiasa menyelesaikan soal-soal yang tidak rutin (non-routine problem). Menurut Kilpatrick, Swafford, dan Zawojewski dalam Wijaya (2012) masalah atau soal-soal tidak rutin sering digunakan dalam kegiatan pemecahan masalah matematika. Menurut Wijaya (2012) soal yang tidak rutin dikategorikan sebagai soal level tinggi karena membutuhkan penguasaan ide, pemahaman konseptual dan tidak menitikberatkan pada perhitungan, oleh karena itu penting sekali memperbanyak soalsoal yang mengandung pemecahan masalah matematis dalam pembelajaran. 
Widjajanti (2009) mengungkapkan mengajarkan pemecahan masalah kepada siswa memungkinkan siswa menjadi lebih analitis dalam mengambil keputusan di dalam hidup oleh karena itu kemampuan pemecahan masalah matematis sangat penting bagi siswa. Matematika akan membantu siswa untuk memahami beberapa informasi atau berita keseharian yang sering dideskripsikan melalui statistik, grafik peningkatan dan penurunan. Kegiatan pemecahan masalah menuntut siswa untuk mengembangkan ide dan pemahaman konsep dengan aktivitas berpikir otak. Pemecahan masalah menuntut proses interpretasi situasi melalui permodelan matematika serta perlu menghubungkan berbagai konsep matematika. National Council of Teachers of Mathematics (NCTM) (2000) mengungkapkan bahwa memecahkan masalah bukan saja merupakan suatu sasaran belajar matematika, tetapi sekaligus merupakan alat utama untuk belajar. Kemampuan pemecahan masalah menjadi fokus pembelajaran matematika di semua jenjang pendidikan, mulai dari Sekolah Dasar sampai Perguruan Tinggi.

Pentingnya kemampuan pemecahan masalah matematis harus digali sejak dini. Pentingnya kemampuan pemecahan masalah matematis juga terlihat dari persaingan dunia global yang menuntut siswa untuk memiliki kemampuan matematis dasar dan teknik berpikir agar dapat hidup secara produktif. Kemampuan pemecahan masalah matematis siswa juga dapat dilihat dari kemampuan awal matematika yang siswa miliki. Jika kemampuan awal matematika siswa telah memenuhi materi prasyarat, siswa dapat menggali kemampuan pemecahan masalah dengan konsep yang siswa telah pelajari. Sejalan dengan pendapat Zakaria dan Yussof (2009) menyatakan pengetahuan awal berperan penting terhadap kemampuan pemecahan masalah. Siswa akan memiliki kemampuan pemecahan masalah tinggi, jika didasari pengetahuan awal yang kuat.

Kemampuan pemecahan masalah matematis dapat dibangun dengan berbagai metode. Guru dapat memberikan latihan soal-soal pemecahan masalah kepada siswa, sehingga siswa dapat mendiskusikan dengan teman sekelas atau sekelompok. Permasalahan yang ada dapat diselesaikan melalui diskusi kelompok. Menurut Suherman (2001), untuk mengembangkan kemampuan siswa dalam pemecahan masalah matematis, hal yang perlu ditingkatkan adalah kemampuan menyangkut berbagai teknik dan strategi pemecahan masalah. Kemampuan berbagai teknik dan strategi pemecahan masalah yang dimaksud adalah kemampuan berpikir siswa dalam mengembangkan ide yang dimiliki. Siswa dapat menyelesaikan soal dengan mengaitkan pemahaman yang telah dimiliki dengan masalah yang terdapat pada soal, serta mencari jalan keluar sampai mendapatkan hasil yang tepat.

Proses penyelesaian masalah matematika menuntut kemandirian siswa, oleh karena itu siswa harus memiliki self confidence yang tinggi dalam belajar. Self confidence adalah sikap positif seorang individu yang merasa memiliki kompetensi atau kemampuan untuk mengembangkan penilaian positif baik terhadap dirinya maupun lingkungan sehingga tidak akan kesulitan mengerjakan soal-soal matematika. Self confidence siswa SMP di Kecamatan Cibodas juga masih rendah, terlihat dari beberapa siswa belum berani dalam mengemukakan pendapat di depan kelas, bertanya kepada guru apabila mengalami kesulitan, dan mengerjakan soal matematika di depan kelas. Siswa dikatakan memiliki self confidence yang rendah jika dirinya meyakini dan memandang bahwa dirinya lemah, tidak dapat berbuat apaapa, tidak memiliki kemampuan, cenderung merasa dirinya selalu gagal, tidak menarik, tidak disukai dan kehilangan daya tarik terhadap hidup

Salah satu cara untuk meningkatkan kepercayaan diri dengan menggunakan berbagai pendekatan dan model pembelajaran yang tepat. Alternatif model pembelajaran matematika yang diduga dapat meningkatkan self confidence siswa dalam pelajaran matematika adalah Model-Eliciting Activities (MEA's). Menurut Chamberlin (2002), pembelajaran matematika dengan MEA's merupakan suatu alternatif pendekatan yang berupaya membuat siswa dapat secara aktif terlibat dalam proses pembelajaran matematika di kelas. Kegiatan MEA's terdiri 
atas empat bagian utama, yaitu: lembar permasalahan, pertanyaan kesiapan, konteks permasalahan, dan proses berbagai solusi melalui kegiatan presentasi. MEA's mempunyai tujuan agar siswa lebih memahami dan mendorong siswa dalam pemecahan masalah, yaitu mendorong siswa membangun model matematika untuk memecahkan masalah yang kompleks, dan sarana bagi guru untuk lebih memahami pemikiran siswa.

Pada Model-Eliciting Activities (MEA's) siswa menghasilkan alat konseptual (rumus atau cara) yang berisi penggambaran eksplisit atau sistem penjelasan yang berfungsi sebagai model dimana siswa memberitahu aspek-aspek penting bagaimana siswa tersebut menginterpretasi situasi pemecahan masalah. Model-Eliciting Activities (MEA's) dan Konvensional melibatkan siswa dalam mencari strategi penyelesaian masalah matematika, sehingga dengan menerapkan kedua model tersebut diharapkan kedua model mampu meningkatkan kemampuan pemecahan masalah matematis siswa melalui diskusi kelompok dan pemberian soal pemecahan masalah matematika.

\section{METODE}

Metode penelitian yang digunakan dalam penelitian ini adalah metode eksperimen dengan menggunakan Treatment by Level 2 x 2 Design dan quasi eksperimen design atau eksperimen semu. Menurut Sugiono (2013) eksperimen semu digunakan karena peneliti tidak mungkin melakukan pengontrolan penuh terhadap variabel yang mempengaruhi pelaksanaan eksperimen.

Variabel yang digunakan dalam penelitian ini adalah variabel terikat yaitu kemampuan pemecahan masalah matematis dan self confidence matematika, variabel bebas yaitu model pembelajaran dan variabel moderator yaitu kemampuan awal matematika. Variabel moderator adalah variabel yang memperkuat dan memperlemah hubungan antara variabel terikat dan variabel bebas (Sugiyono, 2013). Penelitian ini melibatkan dua faktor yaitu model pembelajaran dan kemampuan awal matematika. Kemampuan awal terdiri dari dua taraf yaitu tinggi dan rendah.

Populasi target pada penelitian ini adalah seluruh siswa SMP Negeri di Kecamatan Cibodas, Tangerang tahun pelajaran 2016/2017. Teknik pengambilan sampel yang digunakan pada penelitian ini adalah teknik multi-stage random sampling yaitu Cluster Random Sampling. Penelitian ini mengundi 4 kelas (dua kelas sebagai kelas eksperimen dan dua kelas sebagai kelas kontrol) dan Simple Random Sampling, pengambilan sampel dilakukan secara acak dari populasi, yang memungkinkan setiap siswa berpeluang untuk menjadi sampel penelitian. Subjek yang akan diteliti, diambil 4 kelas dari kelas yang ada di Sekolah Menengah Pertama (SMP) Negeri 9 Tangerang. Empat kelas yang terpilih tersebut, dua kelas diambil sebagai kelas eskperimen dan dua kelas yang lain sebagai kelas kontrol. Jumlah sampel kelas eksperimen 44 siswa dan kelas kontrol 44 siswa. Pengelompokan dilakukan berdasarkan hasil tes kemampuan awal siswa dengan pengambilan acak menurut Naga (2012) $33,3 \%$ dari urutan teratas (untuk siswa kemampuan awal tinggi) dan 33,3\% dari urutan terbawah (untuk siswa kemampuan awal rendah) dimana angka ini dianggap cukup kontra dan reliabel. Kelompok eksperimen diberi perlakuan dengan model pembelajaran Eliciting Activities (MEA's) dan kelompok kontrol diberi perlakuan dengan model pembelajaran konvensional yang digunakan di sekolah kurikulum 2013.

Pada akhir penelitian akan diberikan tes yang sama, yaitu dengan diberikan tes kemampuan pemecahan masalah matematis siswa dan kuesioner self confidence siswa. Kedua instrumen yang digunakan telah diuji validitas dan reliabilitasnya oleh ahli. Data yang diperoleh dari kedua instrumen ini kemudian akan diuji dengan menggunakan uji hipotesis jenis ANOVA dua jalur. Setelah sebelumnya melalui uji prasyarat analisis, yaitu uji normalitas, homogenitas dan kesamaan rata-rata. 


\section{HASIL DAN PEMBAHASAN}

Data skor hasil analisis deskriptif kemampuan pemecahan masalah matematis dan kemampuan awal matematika antara siswa yang diberi perlakuan dengan model MEA's dan siswa yang diberi perlakuan dengan model konvensional dengan menggunakan SPSS 22 dan Ms. Office Excel 2013:

Tabel 1 Analisis Deskriptif Data Kemampuan Pemecahan Masalah Matematis

\begin{tabular}{|c|c|c|c|c|c|c|c|c|c|c|c|}
\hline \multirow{2}{*}{$\begin{array}{c}\text { Kemam } \\
\text { puan } \\
\text { Awal } \\
\text { Matem } \\
\text { atis }\end{array}$} & \multirow[b]{2}{*}{ Nilai } & \multicolumn{5}{|c|}{ Model MEA's } & \multicolumn{5}{|c|}{ Model Konvensional } \\
\hline & & $\begin{array}{c}\text { Banya } \\
\text { k siswa }\end{array}$ & Min & $\begin{array}{c}\text { Ma } \\
\text { ks }\end{array}$ & $\bar{x}$ & DS & $\begin{array}{r}\text { Banya } \\
\text { k siswa }\end{array}$ & Min & Maks & $\bar{x}$ & DS \\
\hline Tinggi & Tes & 22 & 19 & 29 & 25.23 & 2.58 & 22 & 17 & 27 & 21.50 & 2.84 \\
\hline Rendah & Tes & 22 & 15 & 23 & 19.05 & 2.65 & 22 & 16 & 24 & 19.68 & 2.23 \\
\hline Jumlah & & 44 & & & 22.14 & 4.06 & 44 & & & 20.59 & 2.69 \\
\hline
\end{tabular}

Berdasarkan Tabel hasil tes kemampuan pemecahan masalah matematis siswa yang diberi perlakuan dengan Model MEA's dengan jumlah sampel 44 memperoleh rata-rata skor 22,14, serta simpangan baku sebesar 4,06 sedangkan hasil tes kemampuan pemecahan masalah matematis siswa yang diberi perlakuan dengan model konvensional dengan jumlah sampel 44 memperoleh rata-rata skor 20,59, serta simpangan baku sebesar 2,69. Berdasarkan tabel di atas, terlihat bahwa rata-rata kemampuan pemecahan masalah siswa pada kelas eksperimen lebih tinggi dibandingkan dengan rata-rata hasil belajar siswa pada kelas kontrol. Standar deviasi kelas eksperimen lebih tinggi dari standar deviasi kelas kontrol. Artinya, penyebaran data hasil belajar siswa pada kelas eksperimen lebih banyak dari pada kelas kontrol. Hal ini mengidentifikasikan bahwa jika dilihat dari keragaman data masing-masing kelas, maka kemampuan pemecahan masalah matematika pada kelas eksperimen hampir beragam bila dibandingkan dengan kemampuan pemecahan masalah matematika pada kelas kontrol.Skor tes kemampuan pemecahan masalah matematika siswa pada kelas eksperimen dan kelas kontrol dikelompokkan berdasarkan indikator kemampuan pemecahan masalah.

Data hasil uji statistik kemampuan pemecahan masalah matematis dan kemampuan awal matematika antara siswa yang diberi perlakuan dengan model MEA's dan siswa yang diberi perlakuan dengan model konvensional dengan menggunakan SPSS 22 dan Ms. Office Excel 2013 sebagai berikut:

Tabel 2 Hasil Uji ANAVA Dua Jalan Pengaruh Model Pembelajaran dan Kemampuan Awal Matematika Serta Interaksinya Terhadap Kemampuan Pemecahan Masalah Matematis

\begin{tabular}{lcrrrr}
\hline Dependent Variable: & Pemecahan Masalah Matematis & & & \\
\hline Source & $\begin{array}{c}\text { Type III Sum } \\
\text { of Squares }\end{array}$ & df & Mean Square & \multicolumn{1}{l}{ F } & Sig. \\
\hline Corrected Model & $509.273^{\text {a }}$ & 3 & 169.758 & 25.414 & .000 \\
\hline Intercept & 40163.636 & 1 & 40163.636 & 6012.832 & .000 \\
\hline Model & 52.545 & 1 & 52.545 & 7.866 & .006 \\
\hline Kemampuan Awal & 352.000 & 1 & 352.000 & 52.697 & .000 \\
\hline Model * K.Awal & 104.727 & 1 & 104.727 & 15.679 & .000 \\
\hline Error & 561.091 & 84 & 6.680 & & \\
\hline Total & 41234.000 & 88 & & & \\
\hline Corrected Total & 1070.364 & 87 & & & \\
\hline a. R Squared = .476 (Adjusted R Squared =.457) & & & & \\
\hline
\end{tabular}

Hasil analisis data yang diperoleh setelah penelitian, secara keseluruhan pengujian hipotesis yang pertama membuktikan kemampuan pemecahan masalah pada kedua kelompok yang diberi perlakuan berbeda memiliki perbedaan yang signifikan. Hasil analisis data baik dari analisis deskriptif maupun uji statistik, menunjukan bahwa adanya perbedaan yang 
signifikan antara kemampuan pemecahan masalah matematis yang ditinjau dari KAM dengan diberi perlakuan Model MEA's dan konvensional. Hal ini membuktikan bahwa kemampuan pemecahan masalah matematis siswa yang diberi perlakuan dengan model MEA's lebih tinggi dibandingkan dengan siswa yang diberi perlakuan dengan model konvensional.

Hasil analisis data hipotesis kedua menunjukan adanya interaksi antara model pembelajaran dan KAM yang berpengaruh terhadap kemampuan pemecahan masalah matematis siswa. Berpengaruhnya interaksi berarti model pembelajaran dan KAM secara bersama-sama memberikan pengaruh yang signifikan terhadap kemampuan pemecahan masalah matematis siswa atau peningkatan kemampuan pemecahan masalah matematis siswa dipengaruhi oleh kemampuan awal matematika dan model pembelajaran.

Hasil analisis data hipotesis ketiga menunjukan bahwa kemampuan pemecahan masalah matematis siswa yang diberi perlakuan dengan model MEA's lebih tinggi dibandingkan dengan siswa yang diberi perlakuan dengan model konvensional pada siswa yang berkemampuan awal tinggi. Berikut tabel hasil analisis data perbedaan kemampuan pemecahan masalah matematis siswa pada kelompok siswa yang memiliki KAM tinggi:

Tabel 3 Hasil Analisis Data Perbedaan Kemampuan Pemecahan Masalah Matematis Siswa Pada Kelompok Siswa Yang Memiliki KAM Tinggi

\begin{tabular}{|c|c|c|c|c|c|c|c|}
\hline \multicolumn{8}{|c|}{ Independent Samples Test } \\
\hline & & \multicolumn{2}{|c|}{$\begin{array}{l}\text { Levene's Test } \\
\text { for Equality of } \\
\text { Variances }\end{array}$} & \multicolumn{4}{|c|}{ t-test for Equality of Means } \\
\hline & & $\mathbf{F}$ & Sig. & $\mathbf{T}$ & df & Sig. (2-tailed) & Mean Difference \\
\hline \multirow{2}{*}{$\begin{array}{l}\text { Kemampuan } \\
\text { Pemecahan } \\
\text { Masalah } \\
\text { Matematis }\end{array}$} & $\begin{array}{l}\text { Equal } \\
\text { variances } \\
\text { assumed } \\
\end{array}$ & .709 & .405 & 4.555 & 42 & .000 & 3.727 \\
\hline & $\begin{array}{l}\text { Equal } \\
\text { variances } \\
\text { not assumed }\end{array}$ & & & 4.555 & 41.618 & .000 & 3.727 \\
\hline
\end{tabular}

Hal ini terjadi karena pada siswa berkemampuan awal tinggi yang diberi perlakuan dengan model MEA's mampu mengembangkan dan mendorong kemampuan pemecahan masalahnya, sehingga pembelajaran menjadi menantang. Kemampuan Awal Matematika (KAM) siswa yang tinggi menjadikan daya berpikir siswa yang terbentuk akan lebih baik dan membantu siswa dalam menganalisis suatu masalah yang akhirnya dapat memutuskan rencana penyelesaian masalah sampai ke tahap akhir.

Hasil analisis data hipotesis keempat tidak ada perbedaan rata-rata kemampuan pemecahan masalah matematis pada kelompok siswa yang memiliki kemampuan awal rendah, baik diberi perlakuan dengan MEA's maupun dengan model konvensional. Hal ini terjadi karena siswa yang memiliki KAM rendah yang belum memahami materi dasar matematika. Senada dengan pendapat Zakaria dan Yussof (2009) bahwa pengetahuan awal berperan penting terhadap kemampuan pemecahan masalah.

Hasil analisis data hipotesis kelima baik dari analisis deskriptif maupun uji statistik, menunjukan bahwa adanya perbedaan yang signifikan antara self confidence yang diberi perlakuan dengan model MEA's dengan siswa yang diberi perlakuan dengan model konvensional. Hal ini menunjukan bahwa self confidence siswa dalam belajar matematika yang diberi perlakuan dengan model MEA's lebih tinggi dibandingkan dengan siswa yang diberi perlakuan dengan model konvensional. Self confidence yang dibahas adalah self confidence siswa secara keseluruhan, tidak ditinjau berdasarkan KAM siswa. Pembelajaran dengan model MEA's terdapat aktivias dimana siswa disajikan masalah berupa LAS yang dapat mengkonstruk pemahaman siswa sebelum diajarkan oleh guru, pada saat diskusi terdapat diskusi kelompok, setiap siswa dituntut untuk membuat rencana penyelesaian sesuai 
dengan kemampuan yang dimiliki, setelah itu siswa mendisukusikan model matematika mana yang terbaik untuk menyelesaikan masalah tersebut. Siswa juga dilatih dalam kepercayaan diri dan keberaniannya pada saat presentasi di kelas mengemukakan hasil diskusinya, dari sinilah guru dapat melihat self confidence yang dimiliki siswa.

\section{SIMPULAN DAN SARAN}

Berdasarkan hasil pengujian hipotesis dan pembahasan penelitian, dapat disimpulkan bahwa (1) Kemampuan pemecahan masalah matematis siswa yang belajar dengan model Eliciting Activities (MEA's) lebih tinggi dari kemampuan pemecahan masalah matematis siswa yang belajar dengan model pembelajaran Konvensional. (2) Terdapat peningkatan kemampuan pemecahan masalah matematis siswa yang dipengaruhi oleh kemampuan awal matematika dan model pembelajaran (3) Kemampuan pemecahan masalah matematis siswa yang diberi perlakuan Model Eliciting Activities (MEA's) lebih tinggi dibandingkan dengan siswa yang diberi perlakuan model pembelajaran Konvensional pada kelompok siswa yang memiliki kemampuan awal matematika tinggi. (4) Tidak ada perbedaan kemampuan pemecahan masalah matematis siswa yang diberi perlakuan Model Eliciting Activities (MEA's) dengan siswa yang diberi perlakuan model pembelajaran konvensional pada kelompok siswa yang memiliki kemampuan awal matematika rendah. (5) Self confidence siswa dalam belajar matematika yang diberi perlakuan Model Eliciting Activities (MEA's) lebih tinggi dibandingkan dengan siswa yang diberi perlakuan model pembelajaran Konvensional.

Berdasarkan hasil penelitian, diberikan beberapa saran sebagai berikut: Pertama, guru sebaiknya menginformasikan dengan jelas tahap-tahap pelaksanaan model MEA's agar siswa dapat melakukan pembelajaran tersebut dengan optimal dan memberikan arahan kepada siswa yang masih belum jelas dalam menyelesaikan masalah matematis. Kedua, guru matematika diharapkan dapat mengetahui kemampuan awal matematika (KAM) siswa sebelum membagi kelompok dalam belajar agar setiap kelompok memiliki kemampuan yang setara. Ketiga, guru diharapkan memperhatikan cara penilaian pedoman penskoran pada tes kemampuan pemecahan masalah matematis, agar tidak terjadi persepsi berbeda yang mengakibatkan kesalahan perhitungan skor kemampuan pemecahan masalah matematis. Keempat, guru diharapkan memberi lembar penilaian refleksi diri setelah selesai pembelajaran pada siswa KAM rendah, agar siswa dengan KAM rendah dapat menilai dirinya sendiri materi apa yang belum dipahami dan dapat dipelajari dirumah agar tidak tertinggal dengan siswa yang memiliki KAM tinggi. Kelima, guru dapat meningkatkan self confidence dan kemampuan pemecahan masalah matematis siswa dengan menerapkan model MEA's yang menciptakan sikap menyukai matematika dengan menciptakan suasana belajar yang kondusif agar pelajaran menjadi lebih menarik, menantang, menyenangkan dan bermakna.

\section{DAFTAR RUJUKAN}

Chamberlin, S. D. (n.d.). How Does the Problem Based Learning Approach Compare to the Model-Eliciting Activities Approach in Mathematics?

www.cimt.plymouth.ac.uk/journal/chamberlin.pdf

Chambers, P. (2008). Teaching Mathematics Developing as a Reflective Secondary. London: SAGE Publications Ltd.

Davis, R., H. Lawrence, T. Alexander, \& S. L. Yelon. (1974). Learning System Design an Approach to the Improvement of Instruction. New York: McGraw Hill Book Co.

Dick, W. \& Carey, L. (1985). The Systematic Design of Instruction, 2nd Edition. Illinois: Scott, Foresman and Company. 
Gagne, R. M. \& L.J. Briggs. (1979). Principles of Instructional Design. New York: Holt, Rinehart.

Glaser, R. (1962). Psychology and Instructional Technology Training Research and Education. Pittsburgh: University of Pittsburgh Press.

Hamalik, O. (2001). Proses Belajar Mengajar. Bandung: Bumi Aksara.

Herman, H. (2003). Pengembangan Kurikulum dan Pembelajaran Matematika. Malang: UNM.

Heruman. (2007). Model Pembelajaran Matematika. Bandung: PT. Remaja Rosdakarya.

Jossey, Bass Teacher. (2009). Mega-Fun Math Games and Puzzles for the Elementary Grades. USA: John Wiley \& Sons, Inc.

Jurdak, M. (2009). Toward Equity in Quality in Mathematics Education. New York: Springer Science+Business Media, LI.C.

Kemendikbud. (2013). Kurikulum 2013. Jakarta: Kementrian Pendidikan dan Kebudayaan.

Kemendikbud. (2013). Materi Pelatihan Guru Implementasi Kurikulum 2013 Matematika SMP/MTS. Jakarta: Kemendikbud.

Lautser, P. (2012). Tes Kepribadian. Jakarta: Bumi Aksara.

Lesh, R. \& Doerr, H. M. (2003). Beyond Constructivism: Models and Modeling Perspectives on Mathematics Problem Solving, Learning, and Teaching. New Jersey: Lawrence Erlbaum Associates Publishers.

Levy, F. \& Richard J. M. (2004.). The New Division of Labor: How Computers Are Creating the next Job Market. New York: Russell Sage Foundation, Print.

Majid, A. (2009). Perencanaan Pembelajaran. Bandung: PT. Remaja Rosda Karya.

Martinis, Y. (2006). Profesionalisasi Guru dan Implementasi Kurikulum Berbasis Kompetensi. Jakarta: Gaung Persada Press.

Molloy, A. (2010). Coach Your Self Mimpi Tercapai, Target Terpenuhi (Terjemahan Retnadi Nur'aini dari ASPIRATIONS: 8 Easy Steps to Coach Yourself to Succes. Jakarta: Raih Asa Sukses.

Mudjiono, D. (2009). Belajar dan Pembelajaran. Jakarta: Rineka Cipta.

Munaf, S. (2001). Evaluasi Pendidikan Fisika. Bandung: FMIPA UPI.

Naga, D. S. (2004). Ketidaktepatan Penggunaan Validitas Butir dan Koefisien Reliabilitas dalam Penelitian Pendidikan dan Psikologi. JURNAL ILMU PENDIDIKAN, 11(2).

National Council of Teachers of Mathematics. (2000). Principles and Standars for School Mathematics. Reston, VA: NCTM.

National Education Association. (Jumat, 20 Mei 2016 pukul 19.00 WIB). Preparing 21st Century Students For A Gobal Society. Retrieved from http://www.nea.org/assets/docs/A-Guide-to-Four-Cs.pdf

Neill, J. (2005). Wellnes and Outdoor Education. Keynote and Workshop Presentation to the Victorian Outdoor Education Conference. Australia: Essential Learning for Student Well-Being,Geelong Conference Center.

Neill, J. (2005). Wellness and Outdoor Education. Keynote and Workshop Presentation to the Victorian Outdoor Education Conference: Essensial Learning For Student WellBeing. Australia: Geelong Conference Cntre.

Nuraeni, R. (2014)). Penerapan Strategi Pembelajaran Aktif Tipe Kuis Tim untuk Meningkatkan Kemampuan Pemahaman Matematis Dan Self Confidence Siswa SMP. Tesis, UPI Bandung.

Praptiwi \& Jeffry, H. (2012). Efektifitas Metode Kooperatif Tipe GI dan STAD Ditinjau dari Kemampuan Awal. Jurnal Penelitian Pembelajaran Fisika, 3(1).

Prastiti, T. D. (2007). Pengaruh Pendekatan RME dan Pengetahuan Awal terhadapp Kemampuan Komunikasi dan Pemahaman Matematika Siswa SMP Kelas VII. 
Disertasi, Program Doktor Pendidikan Matematika Universitas Terbuka di UPBJJ Surabaya: Tidak diterbitkan.

Pusat Penilaian Pendidikan Badan Penelitian dan Pengembangan Kemedikbud. (n.d.). Kemampuan Matematika Siswa SMP Indonesia Menurut Benchmark Internasional TIMSS 2011.

http://litbang.kemdikbud.go.id/data/puspendik/HASIL\%20RISET/TIMSS/LAPORAN \%20TIMSS\%202011.pdf

Raghunatan, A. (n.d.). Self Confidence. http//www.Psychology4all.com.

Ruseffendi, E. (2006). Pengantar Kepada Membantu Guru Mengembangkan Kompetensinya dalam pengajaran Matematika Untuk Meningkatkan CBSA. Bandung: Tarsito Bandung.

Rusman. (2012). Model-model pembelajaran. Bandung: Rajagrafindo Persada.

Sadat, A. (2013). Implementasi Model Pembelajaran Missouri Mathematics Project dalam Upaya Meningkatkan Kemampuan Pemecahan Masalah Matematis dan Self Confidence Siswa Madrasah Tsanawiyah. Tesis UPI, Bandung: Tidak diterbitkan.

Sagala, S. (2010). Konsep dan Makna Pembelajaran untuk Membantu Memecahkan Problematika Belajar dan Mengajar. Bandung: Alfabeta.

Santyasa, I. W. (2005). Model Pembelajaran Inovatif dalam Implementasi Kurikulum Berbasis Kompetensi. Penataran Guru-guru SMP, SMA, dan SMK se-Kabupaten Jembrana Juni-Juli 2005. Jembrana.

Smaldino, S. E. (2012). Intructional Technology \& Media For Learning diterjemahkan oleh Arif Rahman. Jakarta: KENCANA Prenada Media Group.

Soedjadi. (2000). Kiat Pendidikan Matematika di Indonesia. Jakarta: Dirjen Dikti Dekdikbud.

Soni, G. (2016). Model-Eliciting Activities and Reflection Tools for Problem Solving. Retrieved from http://litre.ncsu.edu/sltoolkit/MEA/MEA.htm

Soni, G. (n.d.). Model-Eliciting Activities and Reflection Tools for Problem Solving. http://litre.ncsu.edu/sltoolkit/MEA/MEA.htm.

Suasatra, I. W. (2009). Pembelajaran Sains Terkini: Mendekatkan siswa dengan lingkungan alamiah dan sosial budayanya. Singaraja: Universitas Pendidikan Ganesha.

Sudjana, N. (2002). Metoda Statistika. Bandung : Tarsito.

Sugiman. (2009). Kemampuan pemecahan masalah matematik siswa smp : problematika dan cara melatihkannya. Prosiding Seminar Nasional Penelitian, Pendidikan dan Penerapan MIPA. Yogyakarta: UNY.

Suharsaputra, U. (2012). Metode Penelitian Kuantitatif, Kualitatif, dan Tindakan Kelas. Bandung: PT. Refika Aditama.

Suherman, E. (2001). Strategi Pembelajaran Matematika Kontemporer. Bandung: JICA-UPI.

Sukayasa. (2012). Pengembangan Model Pembelajaran Berbasis Fase-Fase Polya untuk Meningkatkan Kompetensi Penalaran Siswa Smp dalam Memecahkan Masalah Matematika. Jurnal Aksioma, 1(48).

Sumarmo, U. (2000). Pengembangan Model Pembelajaran Matematika untuk Meningkatkan Kemampuan Intelektual Tingkat Tinggi Siswa Sekolah Dasar . Laporan Penelitian Hibah Bersaing, Bandung: FPMIPA IKIP Bandung.

Syaiful. (2009). Model Pengajaran Untuk Meningkatkan Kemampuan pemecahan masalah matematis pada guru SMP. Seminar nasional jurusan matematika, FMIPA UNY, Jambi. 5 Desember .

Wenas, R. J. (2012). Pengaruh Penggunaan Pendekatan Pembelajaran dan Penilaian Berbasis Kelas terhadap Kemampuan Pemecahan Masalah Matematis setelah Mengontrol Kemampuan Awal Matematika Siswa. Disertasi UNJ, Jakarta: Tidak diterbitkan. 
Widjajanti, D. B. (2009). Kemampuan pemecahan masalah matematis Mahasiswa calon guru matematika Apa dan Bagaimana mengembangkannya. Seminar Nasional, FMIPA UNY,Yogyakarta, 5 Des.

Wijaya, A. (2011). Pendidikan Matematika Realistik (Suatu alternatif pembelajaran matematika). Yogyakarta: Graha Ilmu.

Zakaria, E. \& Yussoff, N. (2009). Attitudes and Problem Solving-Solving Skills in Algebra among Malaysian Matriculation College Students. European Journal Of Social Science, 8(2), 232-245. 